\title{
НОВЫЙ РОД РИПИДОМЕЛЛИД (BRACHIOPODA) ИЗ СРЕДНЕГО ОРДОВИКА МОСКОВСКОЙ СИНЕКЛИЗЫ
}

Брахиоподы среднего ордовика Московской синеклизы представлены в основном родами и видами, общими с фауной Северной Прибалтики (Алихова, 1969). Наряду с ними здесь встречается целый ряд специфических для данного региона брахиопод, которые представляют собой новые, еще не описанные таксоны. К последним относится и описываемый в настоящей статье новый род и вид Eorhipidomella ovalis.

Описанные ниже экземпляры Eorhipidomella ovalis найдены из раз. реза скважины Ростов-IP в интервале $1510-1527$ м, охватывающем. глинистые известняки и мергели с многочисленными брахиоподами и мшанками. Этот интервал расчленяется по брахиоподам на две части. Нижняя часть $(1518-1527 \mu)$ характеризуется в основномпереходящими из нижележащих слоев видами родов Clitambonites, Vellamo, Leptelloidea и других, а также редкими находками Eorhipidomella ovalis. Общий родовой и видовой состав брахиопод и полноеисчезновение Leptelloidea на уровне 1518 м позволяют предположить, что отложения в интервале $1518-1527$ м могут быть сопоставлены с кукрузеским горизонтом $\left(\mathrm{C}_{\mathrm{II}}\right)$ в целом или его верхней половиной прибалтийских разрезов. Верхняя часть $(1510-1518$ м) характеризуется частыми находками Eorhipidomella ovalis (см. таблицу, фиг. 19) и Multicostella sp. nov., по количеству экземпляров, резко преобладающих над всеми другими видами брахиопод. Эти слои совместно с надстилающими мергелями (мощность 4 м), включающими Multicostella sp. nov. и крупные строфомениды, рассматриваются в настоящей статье как возможные возрастные аналоги идавереского горизонта $\left(\mathrm{C}_{\mathrm{III}}\right)$ Прибалтики.

Описанные в статье экземпляры хранятся в Геологическом музееИнститута геологии АН ЭССР в Таллине и во Всесоюзном научноисследовательском геологоразведочном нефтяном институте (ВНИГНИ) в Москве.

Автор признателен В. Прокофьеву (ВНИГНИ), предоставившему для изучения дополнительный материал по данному виду.

Надсемейство Enteletacea Waagen, 1884

Семейство Rhipidomellidae Schuchert, 1913

(emend.' Boucot, Johnson and Walmsley, 1965)

Подсемейство Platyorthinae Harper, Boucot and Walmsley, 1969:

Род Eorhipidomella gen. nov.

Тип рода. Eorhipidomella ovalis gen. et sp. nov. 
Д и а г о з. Раковина небольших размеров, двояковыпуклая, с болеевыпуклой спинной створкой. Длина мускульного поля брюшной створки составляет больше половины длины створки. Отпечатки дидукторов. имеют вид длинных и узких веерообразных лопастей; иногда разделены срединной септой, окаймляющей спереди маленькое аддукторное поле. Замочный отросток трехлопастный. Ребристость тонкая, изортисного. типга.

С p а в н ен и е. Новый род выделен на основе одного вида, имеющегопо признакам подсемейственного значения промежуточное положение между подсемействами Rhipidomellinae Schuchert, 1913 (emend. Boucot, Johnson and Walmsley, 1965) и Platyorthinae Harper, Boucot and Walmsley, 1969. По форме раковины новый род сходен с родами Mendaceilat Cooper, 1930 и Dalejina Havliček, 1953 из подсемейства Rhipidomellinae, а по строению кардиналия и мускульному полю брюшной створки с родом Diceromyonia Wang, 1949 из подсемейства Platyorthinae. Oтметим, что два первых рода рассмотрены некоторыми авторами (Williams, Wright, 1963; Wright, 1965) в качестве синонимов, а роды Mendacella и Diceromyonia отличаются друг от друга прежде всего формой раковины (Harper и др., 1969, с. 82).

От внешне наиболее сходных родов Mendacella и Dalejina новый род отличается сильно развитым трехлопастным замочным отростком, высокой срединной септой спинной створки, относительно меньшей выпуклостью брюшной створки и изортисным типом ребристости. Мускульное поле брюшной створки у Eorhipidomella сходно с таковым у Mendacella; но у первого рода отпечатки дидукторов веерообразны и разделены срединной септой, окаймляющей спереди аддукторное поле. По последним признакам, а также строению кардиналия, в частности по трехлопастному замочному отростку, и сильно развитым утолщениям дна нототириальной полости и брахиофор новый род сравним с родом Diceromyonia (см. Wang, 1949). Eorhipidomella отличается четко от последнего рода формой раковины и изортисным типом ребриетости.

\section{Eorhipidomella ovalis gen. et sp. nov. \\ Таблица, фиг. 1--19; рисунок}

Г о лоти п. Брюшная створка $\mathrm{Br} 4269$, таблица, фиг. 1 и 2 . Идавере-

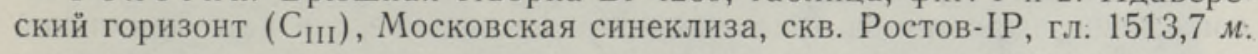

Ди агноз. Раковина небольших размеров, овального очертания; длина брюшной створки составляет ${ }^{4 / 5}$, а длина замочной линии половину наибольшей ширины раковины. Спинная створка в два раза выпуклее брюшной створки. В 2 мм на расстоянии 5 мм от макушки спинной створки насчитывается 8-9 ребрышек.

О писание. Раковина небольших размеров, двояковыпуклая, с более выпуклой спинной створкой. Очертание овальное, вытянутое в ширину; длина брюшной створки составляет в среднем $4 / 5$ наибольшей: ширины створки. Замочная линия в два раза короче нанбольшей ширины, приуроченной к середине раковины. Замочные углы округлые. Передняя комиссура ректимаргинатная или унипликатная.

Скульптура изортисного типа состоит из тонких ребрышек, увеличивающихся в числе путем расщепления и, возможно, частичного вклинивания. В 2 мм на расстояниях 2 и 5 мм от макушки спинной створки насчитывается соответственно 10 и 8-9 ребрышек. Линии нарастания редкие, но четкие, развиты в виде уступов. 
Брюшная створка слабо выпуклая, боковые части уплощены; в середине передней половины створки прослеживается широкий и низкий синус. Макушка маленькая; арея низкая (высотой около 1 мм), апсаклинная, в подмакушечной части слегка вогнутая. Дельтирий треугольный, открытый. Зубы с неглубокими круральными фоссетами и короткими, спереди субпараллельными или расходящимися зубными пластинами. Мускульное поле двухлопастное, длина его больше половины длины створки. Отпечатки дидукторов узкие, длинные, слегка веерообразные, иногда разделены низким валиком, окаймляющим спереди маленькое аддукторное поле. Дно створки по краям ребристое.

Спинная створка в два раза выпуклее брюшной створки. Синус низкий, иногда прослеживается только в задней половине створки. Макушка незаметная; арея плоская, анаклинная до ортоклинной, ниже брюшной
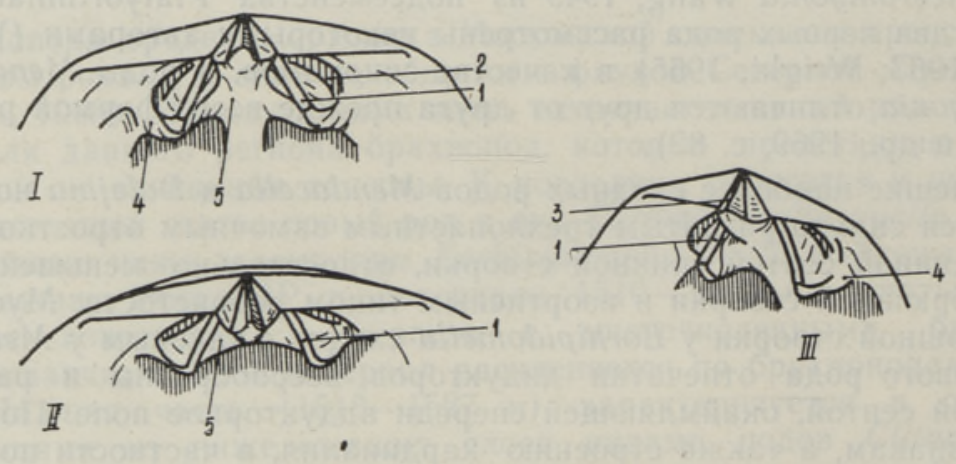

Схемы строения кардиналия Eorhipidomella ovalis gen. et sp. nov.

$I$ - вид с вентральной стороны; $I I$ - вид сзади; $I I I$ - внд с вентролатеральной стороны. 1 - брахиофоры; 2 - зубные ямки; 3 - замочный отросток; 4 - утолщения брахнофор: 5 - утолщение дна нототириальной полости, переходящее в срединную септу.

ареи. Нототирий треугольный, заполнен замочным отростком. Брахиофоры имеют вид толстых, широко расходящихся пластин; со стороны нототириальной полости и спереди они утолщены вторичным раковинным веществом (рисунок). Замочный отросток сильно развитый, трехлопастный, выдается за замочный край. Утолщение дна нототириальной полости переходит в длинную и высокую срединную септу. Зубные ямки имеют вид неглубоких углублений между брахиофорой и задним краем створки. Аддукторное поле субквадратного очертания, передний край его неясный. Дно створки гладкое, краевая ребристость сходна с таковой на брюшной створке.

\section{Таблица}

Фиг. 1-19. Eorhipidomella ovalis gen. et sp. nov.

I и 2 - брюшная створка $\mathrm{Br} 4269$, голотип, внешнее и внутреннее строенне: $3-5$ - брюшная створка из коллекцин ВНИГНИ (обр. № 122), внутреннее строение, вид с антеро-дорзальной " дорзолатеральной сторон; 6 и 7 - внутреннее строенне брюшных сгворок $\mathrm{Br} 4272$ и $\mathrm{Br} 4273$; $8-10$ - брюшная створка из коллекции ВНИГНИ (обр. № 76), внешнее и внутреннее строение, вид сзади; $11-13$ - спинная створка $\mathrm{Br} 4271$, внутреннее строение, вид с антеро-вентральной и постеро-вентральной сторон; 14-18- раковиға из коллекции ВНИГНИ (обр. № 122), внешний внд брюшной и спинной створок, внд сбоку, спереди и сзади; 19 - внешний вид брюшной створки Вr 4270; черными линиямн обведены фрагменты.

Все экземпляры из скважнны Ростов-IP: фиг. $I$ и 2 - гл. $1513.7 \mu$; фиг. 3-5 " $14-18-$ rл. 1526,9 м; фиг. $6,7,11-13-$ гл. 1513,8 м; фиг. $8-10-$ гл. 1512,8 $м$; фиг. $19-$ гл. 1513,3 м. увеличения $\times 3,3$. 

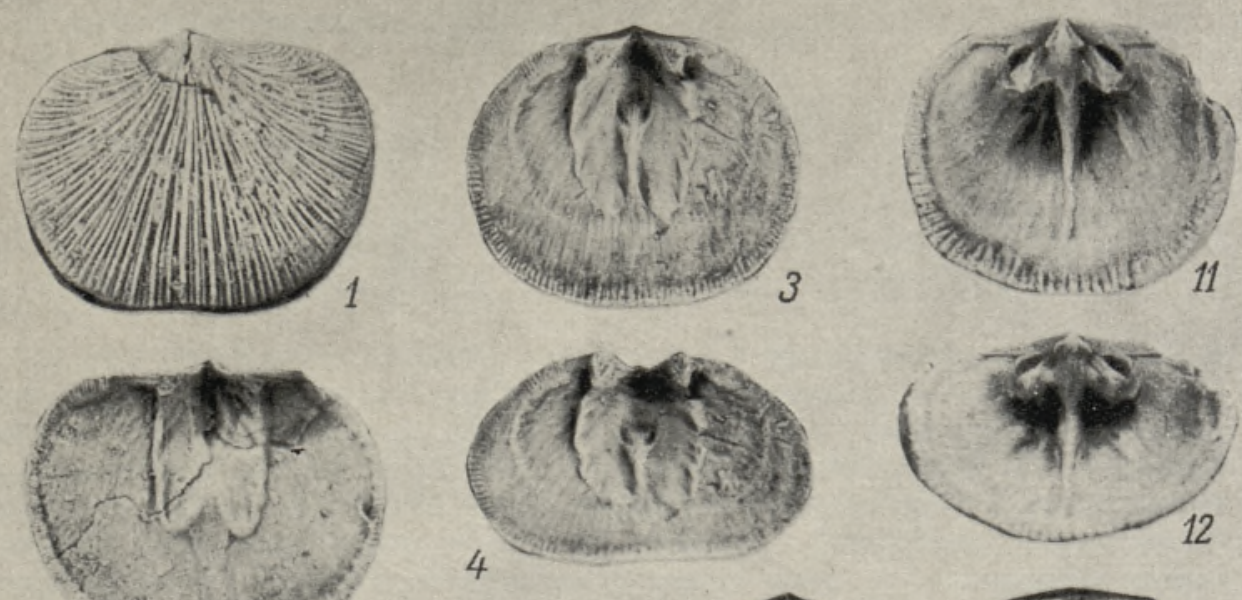

\section{2 yothing}

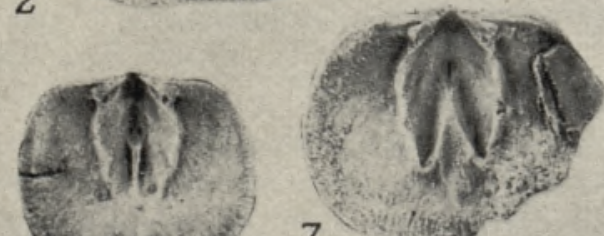

6
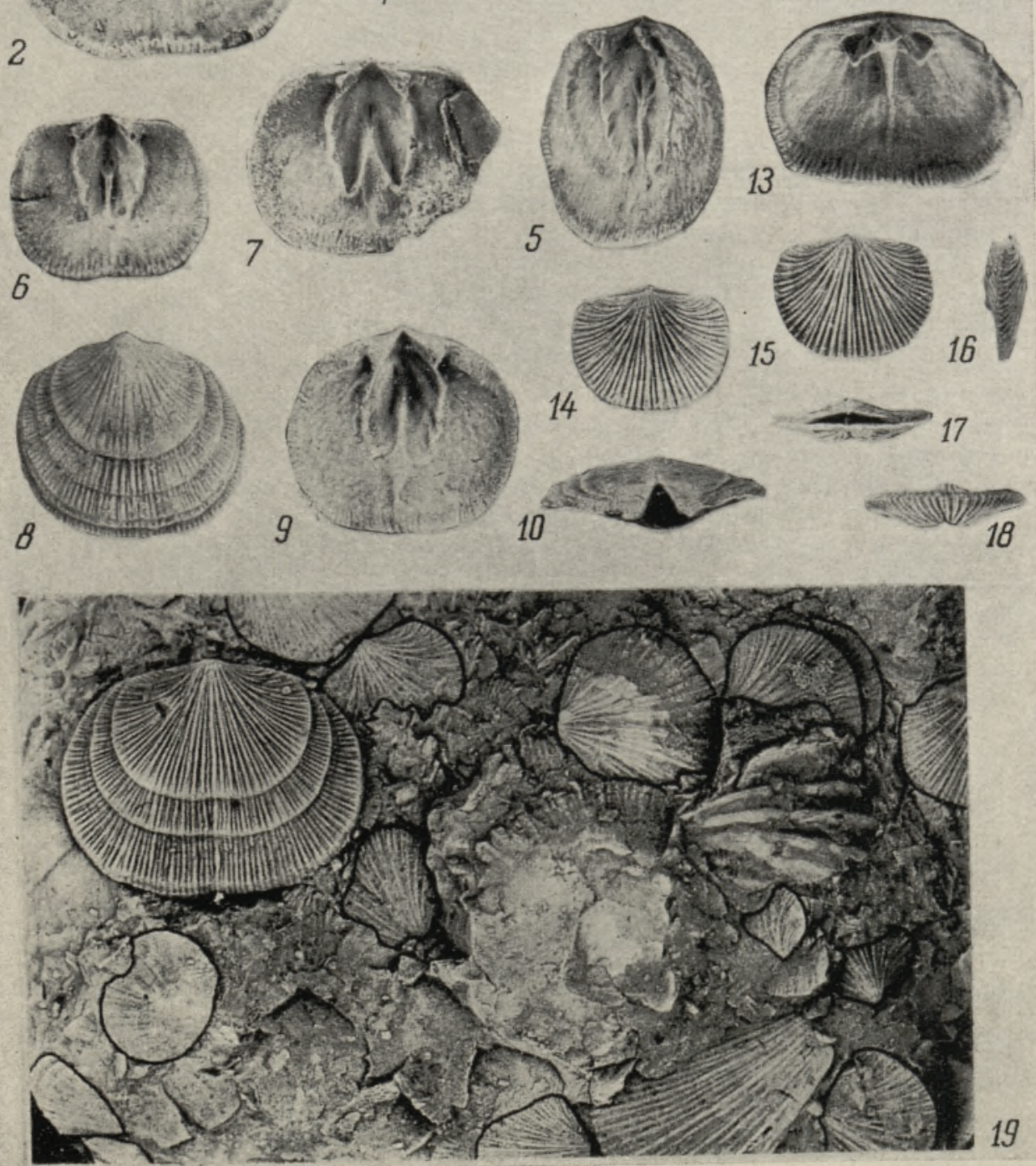

Раковинное вещество пористое.

Размеры, мм:

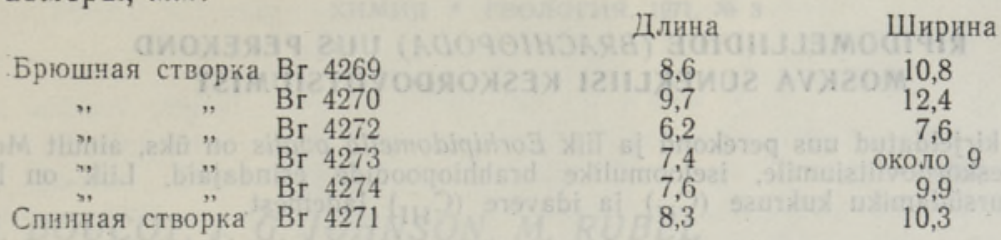

И' з мен чи в ость. Форма раковины и очертание мускульного поля брюшной створки изменяются в ходе роста раковины: у молодых экземпляров брюшная створка очень слабо выпукла, наиболышая ширина прнурочена к задней половине; у взрослых экземпляров на передней половине брюшной створки прослеживается низкий синус, а наибольшая ширина раковины приурочена к ее середине. Очертание мускульного поля брюшной створки изменяется соответственно от овального, суживающего в сторону переднего края (таблица, фиг. 6), до двухлопастного, с субпараллельными, волнистыми боковыми краями (таблица, фінг. 2, 3, 7 и 9).

С равнение. См. сравнение рода.

$\mathrm{P}$ аспространен и е. Кукрузеский $\left(\mathrm{C}_{\mathrm{II}}\right)$ и идавереский $\left(\mathrm{C}_{\mathrm{III}}\right)$ горизонгы центральной части Московской синеклизы.

М а тери ал. Скв. Ростов-IP: $C_{\text {II }}$ : гл. $1524-1527,1$ м, обр. № 122 * (гл. 1526,9 м) - 1 бр. ств.; обр. № $116 *-1$ бр. ств.; гл. $1526,75 \mu-$ 1 бр. ств.; гл. $1521 \mu-1$ цел. рак.; гл. $1519,5 \mu-1$ бр. ств.; гл. $1518-1521 \mu$, обр. № $605 *-1$ бр. ств.; обр. № $606 *-1$ бр. ств.; гл. $1519,2 \mu-1$ сп. ств; $\mathrm{C}_{\mathrm{IH}}$ : гл. $1515-1518$ м, обр. № 91 * 1 бр. ств.; обр. № $99^{*}$-- 2 бр. ств.; обр. № $610^{*}-2$ бр. н 2 сп. ств.; гл. $1517,4 \mu--$ 1 бр. и 1 сп. ств.; гл. 1516,8 $\mu-1$ бр. ств.; гл. 1516,7 $\mu-1$ сп. ств.; гл. $1516,4 \mu-1$ сп. ств.; гл. $1515,9 \mu-4$ бр. и 1 сп. ств.; гл. $1515,7 \mu-$ 2 сп. ств.; гл. $1515,5 \mu-2$ сп. ств.; гл. $1512-1515 \mu$, обр. № 621 * 3 бр. и 2 сп. ств.; обр. № $618^{*}$ - обильно; обр. № $76^{*}$ (гл. 1512,8 м) 2 бр. и 1 сп. ств.; обр. № $80 *-$ обильно; обр. № $83^{*}-2$ сп. и 3 бр. ств.; обр. № $85^{*}-4$ бр. и 4 сп. ств.; обр. № $622 *-2$ сп. ств.; гл. 1514,8 $м$ 1 бр. ств.; гл. 1514,6 $м-3$ цел. рак., 4 бр. и 4 сп. ств.; гл. 1513,9 $м-$ обильно; 1513,7 м -- 1 бр. ств.; гл. 1513,3 $\mu$ - обильно; гл. 1513,0 м - обильно; гл. 1512,4 м - 1 бр. ств.; гл. 1509-1512 м, обр. № 626 * 1 бр. ств.; обр. № $64^{*}-$ обильно; обр. № $69^{*}-1$ бр. ств.; гл. $1510,2 \mu-$ 1 бр. ств.; $1509,9 \mu-4$ бр. и 2 сп. ств.

\section{ЛИТЕРАТУРА}

Алихова Т. Н. 1969. Стратиграфия и брахноподы среднеордовикских отложений Московской синеклизы. М.

Harper Ch. H., B oucot A. J., W a lmslev V. G. 1969. The Rhipidomellid Brachiopod Subfamilies Heterothina and Platyorthinae (new.). J. Paleont., 43, No. 1.

W a n g Yu. 1949. Maquoketa Brachiopoda of Iowa. Geol. Soc. America Mem., 42.

Willi ams A., Wright A. J. T. 1963. The classification of the "Orthis testudinaria Dalman" Group of Brachiopods. J. Paleont., 37, No. 1.

W right A. J. T. 1965. Superfamily Enteletacea Waagen, 1884. In: Treatise Invertebrate Paleontology, part H, Brachiopoda.

Институт геологии

Акауемии наук Эстонской ССР
Поступила в редакцию 5/IV 1971

* Номера образцов из коллекции ВНИГНИ.

7 ENSV TA Toimetised $\mathrm{K} * \mathrm{G}-31971$ 
LINDA HINTS

\section{RIPIDOMELLIIDIDE (BRACHIOPODA) UUS PEREKOND MOSKVA SUNEKLIISI KESKORDOVIITSIUMIST}

Artiklis kirjeldatud uus perekond ja liik Eorhipidomella ovalis on üks, ainult Moskva. sünekliisi keskordoviitsiumile, iseloomulike brahhiopoodide esindajaid. Liik on leitud. Rostov-1 puursüdamiku kukruse $\left(\mathrm{C}_{\mathrm{II}}\right)$ ja idavere $\left(\mathrm{C}_{\mathrm{III}}\right)$ lademest.

\section{LINDA HINTS}

\section{A NEW GENUS OF RHIPIDOMELLID BRACHIOPODS FROM THE MIDDLE ORDOVICIAN OF THE MOSCOVIAN SYNECLISE}

The author presents a description of the new genus and species Eorhipidomella ovalis from the Kukruse $\left(\mathrm{C}_{\mathrm{II}}\right)$ and Idavere $\left(\mathrm{C}_{\mathrm{III}}\right)$ Stages of the Moscovian Syneclise (from the core of the Rostov boring).

Superfamily ENTELETACEA Waagen, 1884

Family RHIPIDOMELLIDAE Schuchert, 1913 (emend.

Boucot, Johnson and Walmsley, 1965)

Subfamily PLATYORTHINAE Harper, Boucot and Walmsley, 1969

Genus Eorhipidomella gen. nov.

T y pe species. Eorhipidomella ovalis gen. et sp. nov.

$\mathrm{D}$ i a g nosis. Unequally biconvex shells, with brachial valve of a greater convexity. Diductor tracks in pedicle valve elongated, subparallel, flabellate, divided or not divided by a median ridge, enclosing adductor impression anteriorly. Cardinal process trilobed. directed posteroventrally. On the pedicle valve median primary costellae (isorthoid: system of costellae).

Eorhipidomella ovalis gen. et sp. nov.

$\mathrm{Hol}$ oty pe. Pedicle valve $\mathrm{Br}$ 4269. Idavere Stage $\left(\mathrm{C}_{\mathrm{III}}\right)$, Rostov boring, depth 1,513.8 $\mathrm{m}$, Moscovian Syneclise. Pl., Figs 1 and 2.

Diagnosis. Shell transversely subelliptical in outline, pedicle valve about four fifths as long as wide and about one half as deep as brachial valve. Hinge line about one half the greatest width. Diductor tracks in pedicle valve one half the length of valve, subparallel, flabellate. Radial ornamentation finely costellate, with counts of $8-9$ : costellae per $2 \mathrm{~mm}$ anterior of dorsal umbo. 